\title{
Do We Question Occupational and Environmental Exposure Adequately in the Outpatient Clinic of Chest Diseases?
}

\author{
Ege Güleç Balbay ${ }^{1}$, Songül Binay ${ }^{2}$, Kezban Özmen Süner ${ }^{3}$, Emine Banu Çakıroğlu ${ }^{1}$, \\ Peri Arbak ${ }^{1}$
}

${ }^{1}$ Department of Chest Diseases, Düzce University, Düzce, Turkey

${ }^{2}$ Clinic of Chest Diseases, Yenimahalle State Hospital, Ankara, Turkey

${ }^{3}$ Department of Internal Medicine, Hacettepe University Faculty of Medicine, Ankara, Turkey

\begin{abstract}
Objective: Detailed examination of occupational and environmental exposure of the individuals and their use of cigarette during history-taking stage in Chest Diseases is crucial. This study was planned to investigate the qualities of occupational anamneses carried out in the Outpatient Clinic of Chest Diseases.

Methods: The recordings of 320 consecutive outpatients (158 female and 162 male) admitted to the Outpatient Clinic of Chest Diseases in the Faculty of Medicine were evaluated retrospectively. During this evaluation, whether occupational histories of the patients had been taken in detail or not and the manner in which questioning was performed regarding environmental exposure and smoking were assessed.

Results: The mean age was $51.6 \pm 17.3$ years in female patients and $55.1 \pm 16.1$ years in male patients. The most common occupations were housewife (37.5\%), farmer (12.8\%) and worker (12.2\%). Detailed occupational history-taking rate was $21.9 \%$ and was found to be higher in males (79\%) than in females (31\%) ( $\mathrm{p}=0.001)$. Of the workers, $60 \%$ had been questioned regarding their current workplaces, while only $10.6 \%$ had been questioned about their previous workplaces. In total, 9 patients $(2.8 \%)$ had been asked about the environment in which they live. The smoking habits had been questioned in $90.6 \%$ of the cases. Of the 290 patients who had been smoking, 183 (63.1\%) had been questioned about the amount of cigarettes smoked in a year (packs.year).
\end{abstract}

Conclusion: It was observed that extensive occupational anamnesis and a history of environmental exposure and smoking were not taken adequately in the Outpatient Clinic of Chest Diseases.

Keywords: Anamnesis, chest diseases, occupation

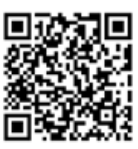

This study was presented as a poster at the 32nd National Congress of the Turkish Respiratory Society in Antalya/Turkey on October 20-24, 2010 and won the e-poster prize

Received Date: 27.01.2014 Accepted Date: 17.02.2014

Address for correspondence Ege Balbay, Department of Chest Diseases, Düzce University, Düzce, Turkey

E-mail: egegulecbalbay@gmail.com

C Copyright 2014 Turkish Respiratory Society (TRS) Eurasian J Pulmonol 2014

DOI: 10.5152/ejp.2014.04557

- Available online at www.eurasianjpulmonol.com

\section{INTRODUCTION}

Comprehensive recording of occupational and environmental exposure of individuals and their use of cigarettes during history-taking stage in Chest Diseases is crucial. Although many patients give vague replies like "self-employed" to the question of "what is your job?", the occupation of each patient should be determined absolutely because many lung diseases are associated with occupation (1).

While taking environmental anamnesis, it is important to determine the patient's current environment where they live, the places where they have lived since birth, and those agents that may cause environmental exposure in these places. The occupation that is actively performed rather than only the title, its setting and working conditions should all be recorded in detail when occupational anamnesis is taken. Therefore, when necessary, the employer and concerned social security institution may be asked for help regarding the individual's working time and conditions, and the quality of the work. Moreover, the results of environmental analysis conducted in the workplace can be obtained from occupational health and safety centres. Also, detailed anamnesis of smoking should be carried out in addition to detailed occupational anamnesis (2).

This study aimed to determine whether occupational anamneses carried out in the Outpatient Clinic of Chest Diseases were adequate or not. 


\section{METHODS}

The recordings of the patients admitted to the Outpatient Clinic of Chest Diseases in the Faculty of Medicine, Düzce University between January 1 and April 30, 2009 were evaluated retrospectively after informed consent was obtained. During this evaluation, whether occupational histories of the patients had been taken in detail or not and the methods used for questioning environmental exposure (the place they live in, the type of heating) and smoking were assessed.

Statistical analyses were performed using SPSS 16.0 (Statistical Package for the Social Sciences) for Windows (Chicago, IL, USA) on a computer. Descriptive statistics (mean, standard error, percentage) were calculated for all data obtained in the study. Chi-square test was employed for comparing the groups. The value of $p<0.05$ was accepted as statistically significant.

\section{RESULTS}

Of 320 consecutive outpatients admitted to the department of chest diseases, 162 (50.6\%) were male. The mean age was $51.6 \pm 17.3$ years for female patients and $55.1 \pm 16.1$ years for male patients.

The 5 most common groups of occupations were housewife (37.5\%), farmer (12.8\%), worker (12.2\%), civil servant (8.4\%) and unknown as not questioned (8.1\%). The distribution of cases according to the groups of occupations is shown in Table 1.

Housewives had not been questioned for animal husbandry and other farm works. Extensive occupational history (exposure, features of workplace) had been obtained from 70 (21.9\%) patients.

The rate of comprehensive occupational history was $79 \%$ (48 of 70 patients) in male patients and 31\% (22 of 70 patients) in female patients and the difference between them was statistically significant $(p=0.001)$. Comprehensive occupational history had been taken in higher rates for the individuals living in cities (49 of 70 patients,

Table 1. Distribution of the cases according to occupational groups

\begin{tabular}{|l|c|}
\hline Occupations & $\mathbf{n}(\%)$ \\
\hline Fousewife & $120(37.5)$ \\
Worker & $41(12.8)$ \\
Civil servant & $39(12.2)$ \\
Non-questioned & $27(8.4)$ \\
Driver & $26(8.1)$ \\
Craftsman & $11(3.4)$ \\
Student & $9(2.8)$ \\
Cleaning staff & $7(2.2)$ \\
Baker & $6(1.9)$ \\
Religious official & $5(1.6)$ \\
Painter & $5(1.6)$ \\
Other (keeper, security guard, & $4(1.3)$ \\
accountant, soldier, carpenter, etc.) & $20(6.2)$ \\
\hline Total & $320(100)$ \\
\hline
\end{tabular}

$70 \%$ ) than for those living in the country (21 of 70 patients, 30\%), but the difference was not statistically significant $(p=0.080)$. Of the 39 workers, 24 (60\%) had been questioned regarding their current workplaces, while 34 (10.6\%) had been asked about their previous workplaces. The anamnesis of previous workplaces had been carried out in higher rates for patients living in cities than for the patients living in the country. However, no statistically significant difference was found $(p=0.064)$.

In total, 9 individuals (2.8\%) had been asked about the environment in which they live. They had never been questioned regarding the type of heating and $90.6 \%$ of cases had been asked about smoking. Of the 290 cases who had smoked, 183 (63.1\%) had been queried about the amount of cigarettes smoked in a year (packs.year).

\section{DISCUSSION}

In this study, it was revealed that, in the anamneses carried out in the Outpatient Clinic of Chest Diseases in a University Hospital, occupational and environmental investigation was inadequate.

Occupational diseases are common and costly (3). Moreover, occupational diseases negatively affect not only worker's health and personal economy, but also the efficiency and profitability of the institution; in other words, all of society's welfare (4).

Among the patients receiving medical care in the Clinics of Internal Medicine, the frequency of hazardous occupational exposure was reported to be $39-75 \%$ (5). Although the history of exposure to hazardous substances is common among workers receiving medical treatment, many occupational diseases cannot be diagnosed because the relationship between occupational exposure and diseases cannot be detected due to inadequate medical screening among workers and mistakes made by healthcare providers (5-8).

There is no standardised questionnaire form designed for occupational anamnesis (9). A comprehensive occupational anamnesis requires listing the works performed until the date of anamnesis chronologically, identifying the levels of exposure, and establishing an association between the primary complaint and occupation (6). In a study in which the quality of occupational anamnesis was investigated among asthmatic patients who were diagnosed in a working period, it was found that $75 \%$ of the 197 adult patients with occupational asthma had occupational anamneses, but these existent anamneses were inadequate (8). In our study, detailed occupational history was taken in $22 \%$ of the patients, but it was obtained in lower rates from women and those living in the country. This may have resulted from the fact that health staff might not have questioned the occupations of women because of having generally considered them as housewives. In spite of the fact that most of the women living in the country are known to engage in farming and animal husbandry, it should be remembered that different information can be obtained from a detailed history.

This rate may be lower than the actual figure since the occupational histories of some patients might not have been recorded, even though they had been taken.

While taking anamnesis, the patient's environment, his/her current occupation and previous works should be questioned in detail (2). Shofer et al. (8) stated in their study that the patients newly diag- 
nosed with asthma were asked about their previous jobs at a rate of $10 \%$. In our study, $10.6 \%$ of the patients admitted to our outpatient clinic had been questioned regarding their previous job.

In a questionnaire survey conducted by Schwartz et al. (10), occupational exposure of 554 patients receiving primary care service was investigated and it was found that $75 \%$ of patients were exposed to toxic agents at least once and $30 \%$ were exposed to at least four different toxic agents (10). In this study, although it is known that the housewives in Düzce are busy with animal husbandry and other farm works, they were not asked about their duties in farming and animal husbandry.

It is known that biomass exposure can cause chronic obstructive pulmonary disease (COPD), asthma and interstitial lung diseases (11-14). In our study, we noticed that patients had never been asked about the type of heating.

Our study had some limitations, including the fact that it is a single-centre study, evaluation was only performed for those anamnesis obtained from the Outpatient Clinic of Chest Diseases of a University Hospital, the small study population, and the short study time. Therefore, no evaluation was performed of whether there was any difference among the outpatient clinics in public hospitals, private hospitals, occupational disease hospitals and training and research hospitals in terms of occupational and environmental anamneses or not. Moreover, for the same reasons, the anamneses of pulmonologists, educators and a few occupational therapists could not be compared.

\section{CONCLUSION}

In our study, it was observed that comprehensive occupational anamnesis and history of environmental exposure and smoking were not adequately taken in our outpatient clinic of chest diseases. It is suggested that deficiencies and errors in taking anamnesis will affect diagnostic processes in a negative way. Also, since taking detailed occupational anamnesis requires a long time, occupational anamnesis forms should be designed and the patient should complete these forms alone, which may contribute to the procedures performed by a physician. We think that taking anamnesis of occupational and environmental exposure should be more focused both theoretically and practically during the education of assistant students.

\section{Ethics Committee Approval: N/A}

Informed Consent: Written informed consent was obtained from patients who participated in this study.

Peer-review: Externally peer-reviewed.

Author Contributions: Concept - E.G.B., P.A.; Design - P.A., S.B.; Supervision - E.G.B., P.A.; Resource - P.A., K.Ö.S.; Materials - S.B., K.Ö.S.; Data Collection\&/ orProcessing - S.B., K.Ö.S.; Analysis\&/orInterpretation - E.G.B., E.B.Ç; Literature Search - E.G.B., E.B.Ç.; Writing - E.G.B., E.B.Ç.; Critical Reviews - P.A.

Conflict of Interest: No conflict of interest was declared by the authors.

Financial Disclosure: The authors declared that this study has received no financial support.

\section{REFERENCES}

1. Küçükusta AR. Göğüs hastalıkları temel bilgiler, klinik muayene, tanı yöntemler.1 baskı. İstanbul: Nobel Tıp Kitabevi; 2001.

2. Akciğer Hastalıklarında Maluliyet Değerlendirme Rehberi. Turk Thorac J 2005; 6: 1-2.

3. Blanc $P$, Eisner $M$, Israel $L$, Yelin $E H$. The association between occupation and asthma. Chest 1999; 115: 1259-64.

4. Ding $Q$, Schenk L, Hansson SO. Occupational diseases in the people's Republic of China between 2000 and 2010. Am J Ind Med 2013; 56: 1423-32.

5. Harber $P$, Mullin, M, Merz, B, Tarazi M. Frequency of occupational health concerns in general clinics. J Occup Environ Med 2001; 43: 939-45.

6. Newman LS. Occupational illness. N Engl J Med.1995; 333: 1128-34.

7. Landrigan PJ, Baker, DB. There cognition and control of occupational disease. JAMA 1991; 266: 676-80.

8. Shofer S, Haus BM, Kuschner WG. Quality of occupational history assessments in working age adults with newly diagnosed asthma. Chest 2006; 130: 455-6.

9. Is there a standardized questionnaire for obtaining an occupational history? Occup Environ Med 1997; 39: 401.

10. Schwartz, DA, Wakefield, DS, Fieselmann, JF, Berger WM, Zeitler R. The occupational history in the primary care setting. Am J Med 1991; 90: 315-9.

11. Sezer H, Akkurt I, Guler N, Marakoğlu K, Berk S. A case-controlstudy on the effect of exposure to different substances on the development of COPD. Ann Epidemiol 2006; 16: 59-62.

12. Çımrın AH, Karaman C. Does exposure to biomass and occupational dust can be causative for asthma among women? Tuberk Toraks 2011; 59 : 388-91.

13. Mishra. Effect of indoor air pollution from biomass combustion on prevalence of asthma in theelderly. Environ Health Perspect 2003; 111: 71-8.

14. Kara M, Bulut S, Tas F, Akkurt I, Seyfikli Z. Evaluation of pulmonary changes due to biomass fuel susing high-resolution computed tomography. Eur Radiol 2003; 13: 2372-7. 